\title{
Experimental Study of Indonesian Low-Cost Glass Fiber Reinforced Elastomeric Isolators (GFREI)
}

\author{
Tavio", and Usman Wijaya* \\ ${ }^{\#}$ Department of Civil Engineering, Institut Teknologi Sepuluh Nopember (ITS), Surabaya, Indonesia \\ E-mail: tavio_w@yahoo.com
}

*Department of Civil Engineering, Tarumanagara University, Jl. S. Parman No. 1, Jakarta, 11440, Indonesia

E-mail: usman.wijaya@deltakoni.co.id

\begin{abstract}
In this research, four specimens of elastomeric base isolators were tested. They were named as A1, A2, B1, and B2. The type $A$ and $B$ elastomeric isolators were made from the hyperelastic rubber with the hardness of 40 and 60 , respectively, according to the durometer scale shore A. Prior to the making of elastomeric isolators, both rubber categories (40 and 60$)$ were tested to obtain the mechanical properties of these types of hyperelastic rubbers. testing of hyperelastic rubbers and elastomeric isolators were carried out following BS EN 15129:2009 requirements. The A1 and B1 specimens were tested under vertical load. For lateral load tests, double shear tests were carried out. Specimen A1 which has been tested under vertical load previously was used to be combined with Specimen A2 and tested under lateral load. This double shear test was also conducted to Specimens B1 and B2 in which B1 has been tested earlier under vertical loading. From the results of the hyperelastic rubber tests, the elongation at the breaking of type A and B rubbers were more than 500 and 400 percent with the maximum stress of 8.8 and $6.2 \mathrm{MPa}$, respectively. While the testing results of type $B$ elastomeric isolators showed better damping ratio than type $A$, the effective stiffnesses of type $A$ elastomeric isolators were found higher than type B. From the test results; it can also be shown that higher-story buildings, which have high axial forces, might use type $B$ elastomeric isolators which have higher hardness and damping ratio, whereas low-rise buildings with low axial forces can use type A elastomeric isolators. Thus, it can be concluded that the Indonesian rubber has a bright future and has a strong potential to be developed for use in the production of low-cost elastomeric isolators.
\end{abstract}

Keywords - earthquake; effective stiffness; elastomeric isolators; damping ratio; hyperelastic rubber; seismic.

\section{INTRODUCTION}

Indonesia has a very high earthquake potential. To reduce the risk of building damage during an earthquake, the base isolator can be an effective solution. There have been many studies on base isolators for high rise buildings, but there is not much research on base isolators for residential buildings. Furthermore, in reality, particularly in Indonesia, the population of residential housings is far more than that of the high-rise buildings. Hence, there is an urgency of research on the base isolators for residential buildings [1].

The use of base isolators in multi-story buildings has been proven to provide better performance in reducing damage during an earthquake. When an earthquake occurs, the base isolators might extend the building's natural period, especially residential-landed houses during an earthquake that have a short natural time period. Thus, they are more susceptible to damage or even collapse, and this can be solved by the introduction of the base isolators which might increase the natural time period [2]-[4].
The biggest issue in the use of base isolators in developing countries like Indonesia is the very expensive price, and thus, unaffordable. This study aims to come up with the idea of introducing the application of low-cost base isolators. The way to reduce the production costs is by using the local rubber products to replace the steel plates with perforated glass fiber sheets. The application of the local rubbers has a great potential to improve the country's economy since Indonesia is the second-largest rubber- producing country in the world after Thailand [5]. Besides, other advantages of local hyperelastic elastomeric rubber are their mechanical properties are better than those of imported products. As to the reinforcement, the perforated glass fiber sheets are usually used in the automotive industry. However, in the paper, they are used as reinforcement instead of steel plates to lighten the weight, but most importantly to reduce the production costs of the base isolators [6].

In a previous study by Habieb et al. [6], carbon fiber reinforcement was introduced in the base isolators, and it was able to replace the stiffness of steel plates and the rubber used 
was treated very well with high technology [6]. Whereas in the study, the steel plate or carbon fiber layers were replaced with perforated glass fiber layers to reduce the production costs in the hope that the decrease in stiffness was not so problematic because the base isolator was intended for houses. However, the mechanical properties of the local rubber (based on the uniaxial tension test) produced also by the local technology showed excellent hyperelastic properties that can be used for the development of low-cost base isolators.

In the study, the axial design load is $66 \mathrm{kN}$; the dimensions of the base isolator are the $200-\mathrm{mm}$ diameter and $150-\mathrm{mm}$ overall depth. The perforated plates are 1-mm thick; the glass-fiber layer number is 13 , the rubber layers are $10-\mathrm{mm}$ thick, the rubber layer number is 14 , and each end plates are $5 \mathrm{~mm}$ thick. Tastings are under BS EN 15129-2009.

\section{A. GFREI Effective Stiffness}

The comparison of vertical to horizontal stiffness of an elastomeric base isolator results in the bending behavior of the isolator. For that reason, the perforated glass fiber is needed between the layers of rubber. This is to prevent lateral rubber buckling in multilayer. The vertical stiffness can be calculated by Equation 1 [7].

$$
K_{V}=\frac{E_{c} A}{t_{r}}
$$

For circular elastomeric isolators, $E_{c}$ depends on the shape factor $(S)$. It can be calculated by Equation 2 [7].

$$
E_{c}=6 G S^{2}
$$

Then for the horizontal stiffness, $K_{H}$ can be calculated using Equation 3 [7].

$$
K_{H}=\frac{G A}{t_{r}}
$$

From the hysteresis loop, the effective stiffness is determined as calculated using Equation 4 [8].

$$
K_{e f f}=\frac{\left(F_{\text {max }}-F_{\text {min }}\right)}{\left(d_{\text {max }}-d_{\text {min }}\right)}
$$

\section{B. GFREI Equivalent Damping Ratio}

Damping ratio $(\beta)$ is determined from the hysteresis loop in the relation of force to displacement and the curve area of the hysteresis loop is the energy dissipated. The loop area can be solved by the Bouc-wen model [9]. The damping ratio is obtained by Equation 5 [10].

$$
\beta=\frac{W_{d}}{\left(4 \pi W_{s}\right)}
$$

$W_{d}$ is obtained from the hysteresis loop dissipated energy that can be solved using the Bouc-wen model [9]. Then $W_{s}$ can be determined by Equation 6 [10].

$$
W s=\frac{\left(K_{e f f}\left(\Delta_{\max }\right)^{2}\right)}{2}
$$

$\Delta_{\max }$ is the average of positive and negative displacement as calculated by Equation 7 [11].

$$
\Delta_{\max }=\frac{\left(\Delta^{+}+\left|\Delta^{-}\right|\right)}{2}
$$

The curve of the hysteresis area in the force and displacement can be seen in Figure 1.

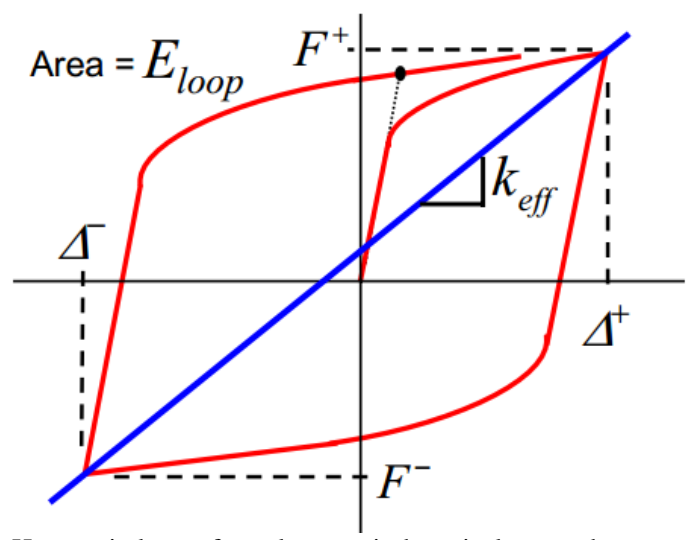

Fig. 1 Hysteresis loop of an elastomeric base isolator under reverse cyclic loading [12]

\section{MATERIALS AND METHOD}

\section{A. Geometric Properties}

The materials used in the study were the hyperelastic rubber and perforated glass fiber composite. There were two types of base isolator samples tested, namely types A and B (rubber hardness 40 and 60 from durometer test shore A), respectively. The geometric properties are described in more detail in Table I.

TABLE I

GEOMETRIC PROPERTIES

\begin{tabular}{|l|c|c|c|c|}
\hline Description & \multicolumn{2}{|c|}{ Type A } & \multicolumn{2}{c|}{ Type B } \\
\hline Specimen & A1 & A2 & B1 & B2 \\
\hline Test & Vertical & Horizontal & Vertical & Horizontal \\
\hline & & & & \\
\hline Diameter (mm) & 200 & 200 & 200 & 200 \\
\hline Depth (mm) & 140 & 140 & 140 & 140 \\
\hline Rubber layer & 14 & 14 & 14 & 14 \\
\hline $\begin{array}{l}\text { Rubber width } \\
\text { (mm) }\end{array}$ & 10 & 10 & 10 & 10 \\
\hline $\begin{array}{l}\text { Glass fiber } \\
\text { (GF) layers }\end{array}$ & 13 & 13 & 13 & 13 \\
\hline GF width (mm) & 1 & 1 & 1 & 1 \\
\hline $\begin{array}{l}\text { Total height } \\
\text { (mm) }\end{array}$ & 150 & 150 & 150 & 150 \\
\hline End plate (mm) & 5 & 5 & 5 & 5 \\
\hline
\end{tabular}

The multilayer section of rubber composite with perforated glass fiber is shown in Figure 2. Figure 3 shows the perforated glass fiber used for elastomeric base isolators in the study. 

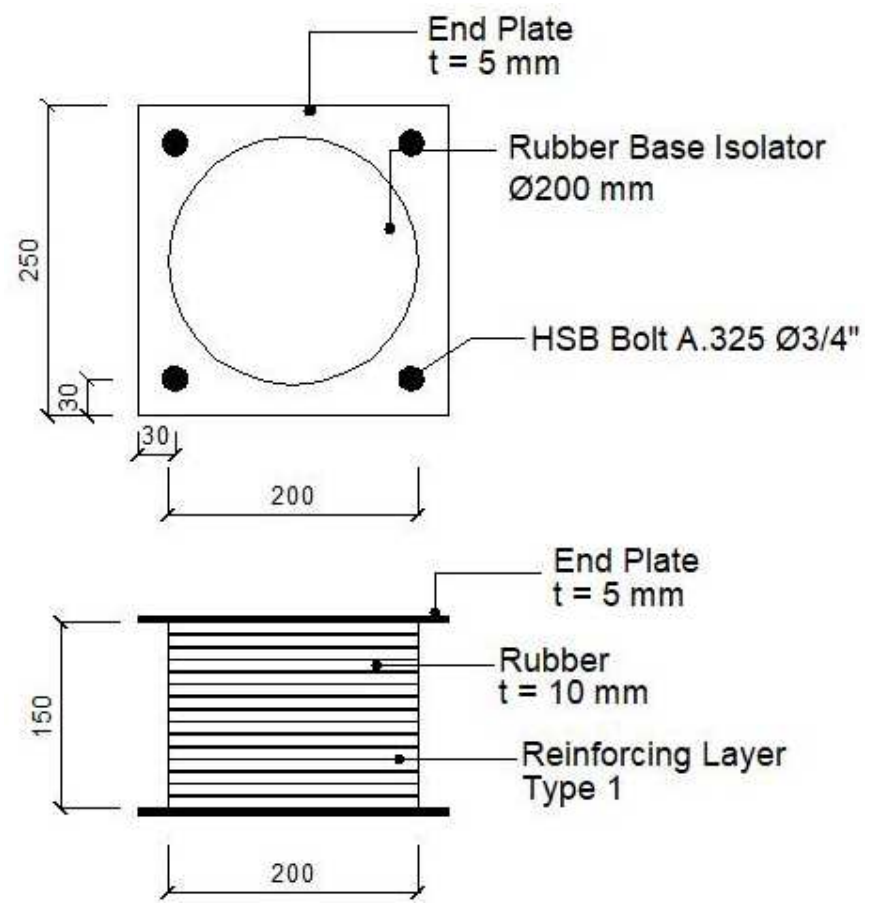

Fig. 2 Cross-section and elevation of multilayer elastomeric base isolator

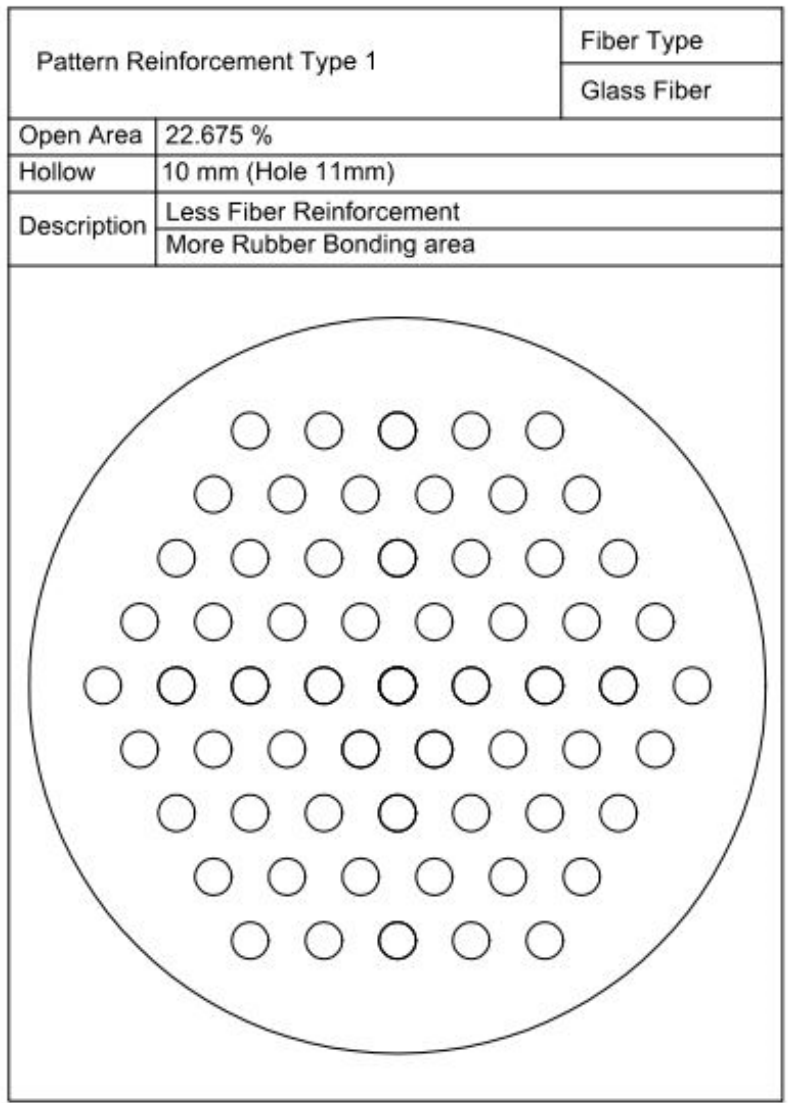

Fig. 3 Perforated glass-fiber reinforcement of multilayer elastomeric base isolator

\section{B. Mechanical Properties}

The mechanical properties of the hyperelastic rubber and perforated glass fiber used in the study were tested previously $[13,14]$ as shown in Figures 4 and 5. The test results are provided in Table II.
TABLE II

MECHANICAL PROPERTIES

\begin{tabular}{|l|c|c|}
\hline Description & Type A & Type B \\
\hline Hardness (shore A) & 40 & 60 \\
Elongation at break & $>500 \%$ & $>400 \%$ \\
Elastomer shear modulus $(G)$ & $0.55 \mathrm{MPa}$ & $0.70 \mathrm{MPa}$ \\
Young's modulus of glass fiber & $4200 \mathrm{MPa}$ & $4200 \mathrm{MPa}$ \\
Poisson ratio of glass fiber & 0.21 & 0.21 \\
\hline
\end{tabular}

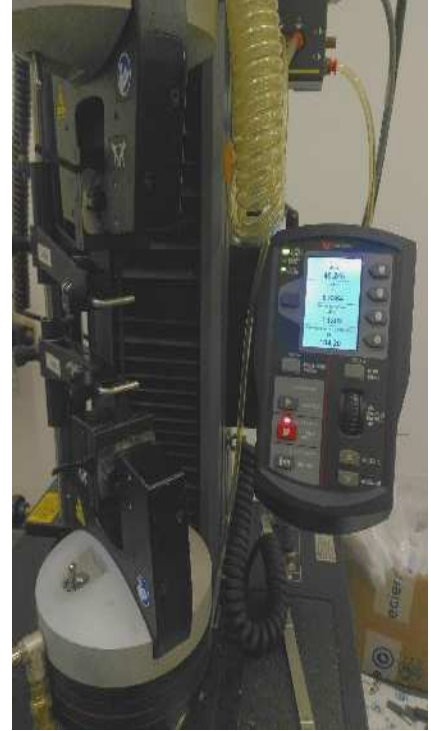

(a)

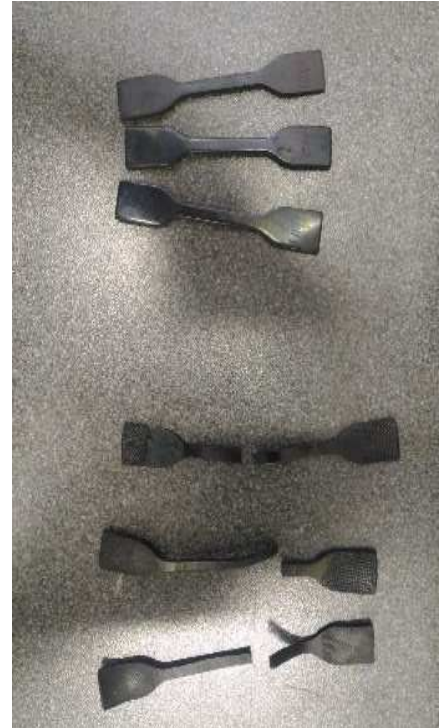

(b)
Fig. 4 Hyperelastic uniaxial tension test: (a) Testing on progress, (b) Samples before and after testing

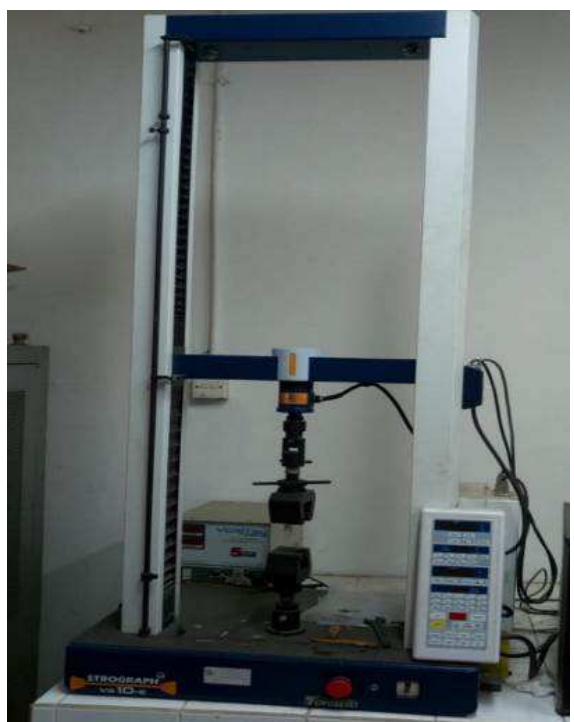

Fig. 5 Glass fiber tension test

\section{Test Method}

The test procedure was carried out based on BS EN 15129:2009 [15].

1) Vertical test: The specimen is tested in the vertical direction with force control. The procedure of the vertical experimental test is as follows [15]: 
- The specimen is loaded up to $66 \mathrm{kN}$ of vertical force in three fully-reversed cycles.

- The loading rate is approximately $25 \mathrm{kN} / \mathrm{sec}$.

- The maximum axial force should be applied to the elastomeric isolator and released before any measurements are taken.

- After the first loading, the maximum axial force, as specified $66 \mathrm{kN}$ should be applied progressively with a minimum of five increments at a rate of $5 \pm 0.5$ $\mathrm{MPa} /$ minutes.

- The specimen is loaded up to $66 \mathrm{kN}$ vertical force in three fully-reversed cycles.

- The vertical displacement must be measured at $1 / 3$ of the maximum load and the maximum load.

- The loading pattern of the vertical test is shown in Figure 6.

- The vertical test setup can be seen in Figure 7.

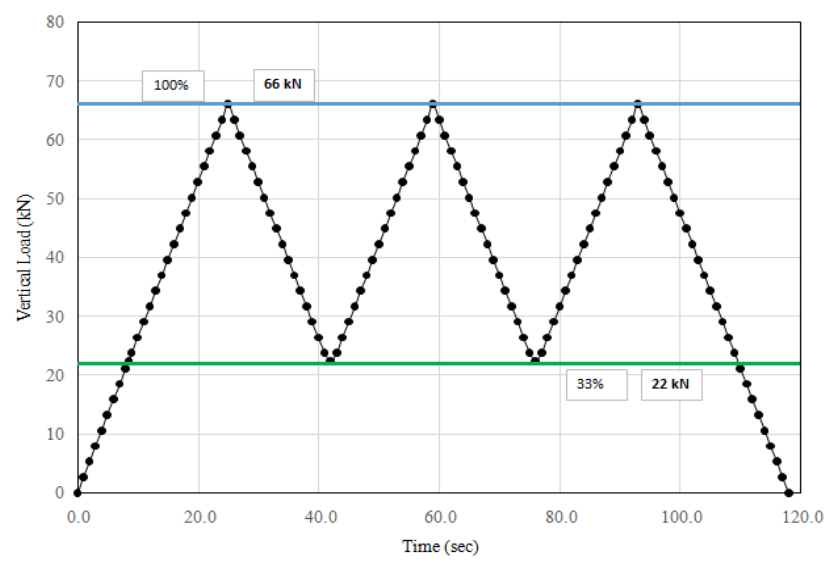

Fig. 6 Loading pattern of vertical test

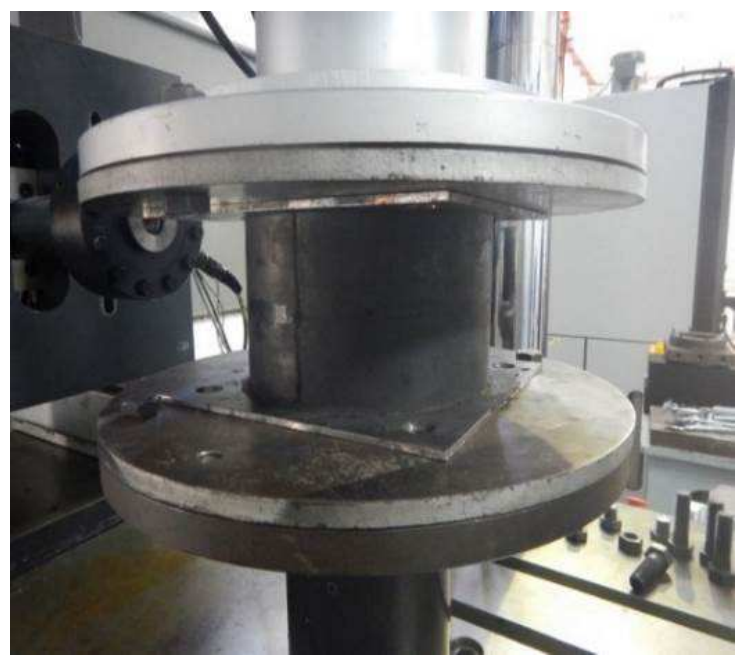

Fig. 7 Vertical test setup on MTS 322 servo-hydraulic machine

2) Horizontal test (a combination of lateral and vertical loads): The procedure of horizontal experimental test is as follows [15]:

- Each test shall be carried out at least twice using different test isolator in each case. The frequency of cyclic lateral displacement subjected to the specimen is $0.5 \mathrm{~Hz}$ or $2 \mathrm{sec} / \mathrm{cyclic}$ or at least $0.01 \mathrm{~Hz}$.

- Vertical displacement shall be measured directly between the load platens of the machine.
- The lateral displacement should be measured along a line of the horizontal loading direction.

- The equipment should be applied a sinusoidal or triangular deformation.

- The horizontal load should be measured in the case of a double- isolator configuration by the transducer between the isolator and the reaction support.

- The lateral load plane should remain within $+0.08 \mathrm{rad}$ (4.5 degrees).

- The axial load should be applied under load control and should be maintained constant.

- The horizontal load should be applied under horizontal displacement control.

- The floating platens should be such that they do not rotate about a vertical axis more than $0.08 \mathrm{rad}$ and move orthogonally to the loading direction more than $10 \%$ lateral displacement.

- The loading pattern of the horizontal test is shown in Figure 8.

- The horizontal test setup can be seen in Figure 9.

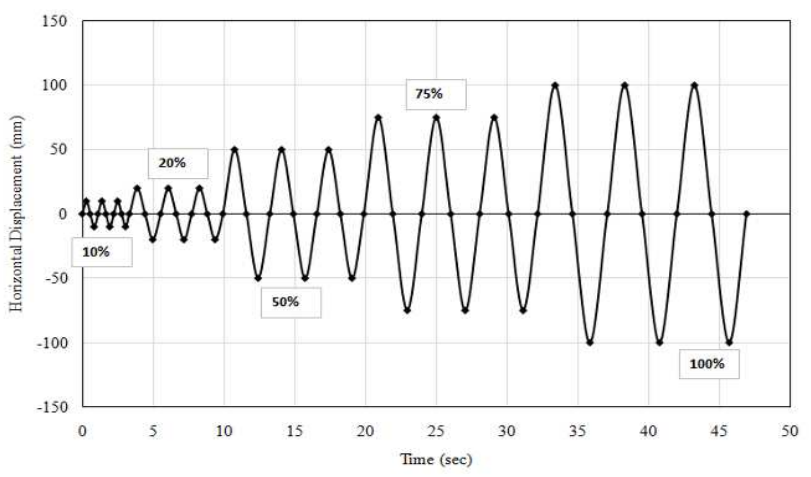

Fig. 8 Loading pattern of horizontal test

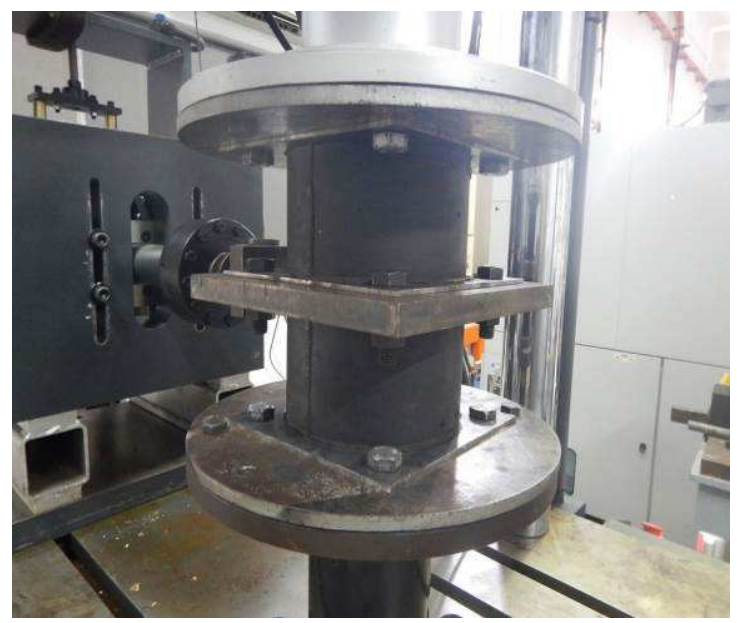

Fig. 9 Horizontal test setup on MTS 322 servo-hydraulic machine

\section{RESULTS AND DISCUSSION}

\section{A. Elongation at Break of Hyperelastic Rubber}

From the tensile test results of hyperelastic rubber types A and B (hardness 40 and 60 scale durometer shore A, respectively), it was found that the hyperelastic rubber-type A has a stress and elongation at break higher than type B. 
However, type B rubber has a hardness and shear modulus higher than type A. This means that the increase in stressstrain of the hyperelastic rubber is not linear with the increase of the hardness and shear modulus. The results of the tensile tests show that the lowest hardness did not produce the lowest stress since the increase of the hardness is not linear with the increase of the stress. The stress-strain curves of the hyperelastic rubber types A and B can be seen in Figure 10.

The local hyperelastic rubbers selected in the study for research were those with the compositions of hardness 40 and 60 . The main reason is that the local hyperelastic rubber with low hardness category (type A) has a high strain but has a low stiffness, which is very suitable for typical low-rise buildings since they experience small axial load and has a short natural fundamental period. Vice versa, the hyperelastic rubber with high hardness category (type B) is suitable for high-rise buildings.

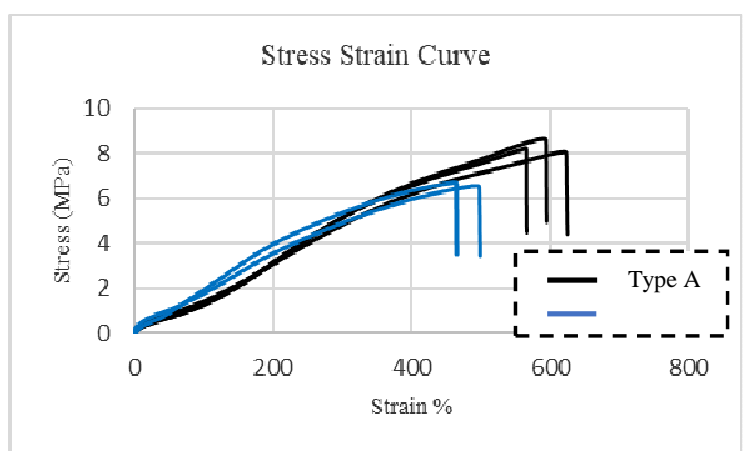

Fig. 10 Stress-strain curves of types A and B hyperelastic rubber

\section{B. Dissipated Energy of Isolator}

In the vertical and horizontal displacement curves in Figures 11 and 12, the area of the hysteretic loop illustrates the dissipated energy used to calculate the damping ratio in Equation 5. The Bouc-wen model was used to calculate the area of the hysteretic loop expressed as $W_{d}$ in Equation 5. The results of the calculation of the area of the hysteretic loop by Equation 5 are listed in Table III.

From the hysteretic loop of force vs displacement, a straight line can be drawn and by using the trigonometric equation, the effective stiffness of the elastomeric isolator can be obtained, or it can be solved by Equation 4 where the axial force difference is divided by the displacement difference. The results are given in Table III.

From Table III, it is shown that a good elastomeric base isolator produces a vertical stiffness ratio of 100 times of its horizontal stiffness.

TABLE III

EXPERIMENTAL EVALUATION

\begin{tabular}{|c|c|c|c|}
\hline Sample & $\begin{array}{c}\text { Horizontal } \\
\text { Stiffness, } \boldsymbol{K}_{\boldsymbol{h}} \\
(\mathbf{k N} / \mathbf{m})\end{array}$ & $\begin{array}{c}\text { Effective } \\
\text { Stiffness, } \boldsymbol{K}_{\text {heff }} \\
(\mathbf{k N} / \mathbf{m})\end{array}$ & $\begin{array}{c}\text { Damping } \boldsymbol{\xi} \\
(\boldsymbol{\%})\end{array}$ \\
\hline $\mathrm{A} 1$ & 33.11 & 499.75 & 4.18 \\
\hline $\mathrm{A} 2$ & 33.11 & 499.75 & 4.18 \\
\hline $\mathrm{B} 1$ & 42.14 & 442.42 & 9.41 \\
\hline $\mathrm{B} 2$ & 42.14 & 442.42 & 9.41 \\
\hline \multicolumn{4}{|c|}{ Average vertical stiffness: $\mathbf{4 0 4 5} \mathbf{~ k N} / \mathbf{m}$} \\
\hline
\end{tabular}

From the two hysteretic loops of the two types of rubber tested, it can be seen that type B rubber has a loop area higher than that of type A which means that type B rubber has a higher damping value than type A rubber (see Table III).

\section{Horizontal Test Results}

The horizontal tests of the elastomeric base isolators were performed by a combination of compression and lateral shear test. The specimens tested were samples A1 and A2. The test results under the BS EN 15129:2009 are shown in Figure 11.

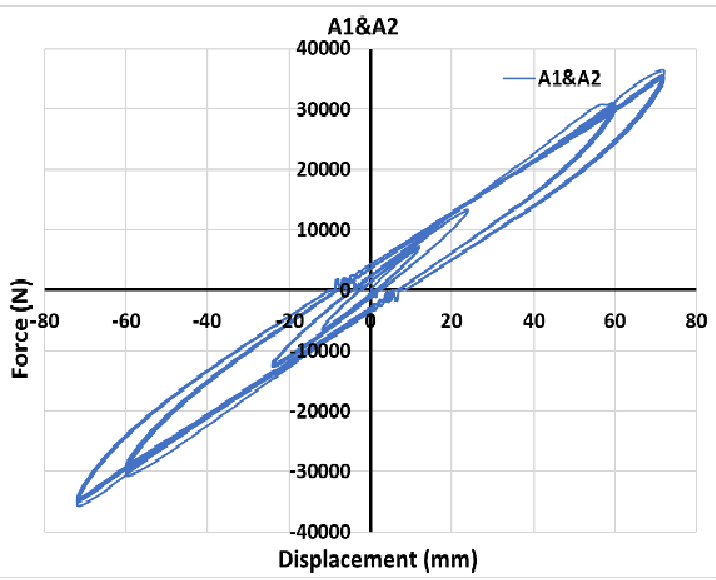

Fig. 11 Hysteretic curves of samples A1 and A2 under a combination of compression and shear test

Another formula selected for elastomeric rubber was typed B. The difference between types $\mathrm{A}$ and $\mathrm{B}$ is the material properties of rubbers. The horizontal test of the elastomeric base isolators was performed by a combination of compression and shear test. The specimens tested were samples B1 and B2. The test results can be seen in Figure 12.

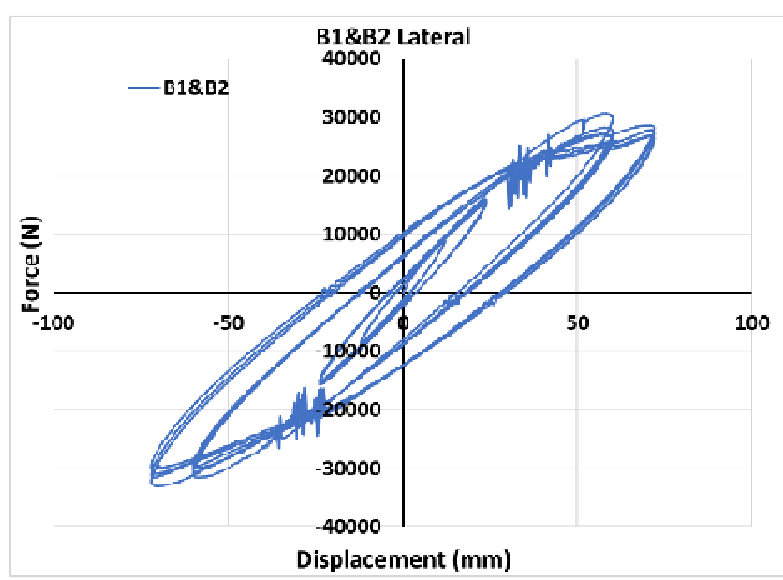

Fig. 12 The hysteretic curve of samples B1 and B2 under a combination of compression and shear test

From the horizontal test, the results shown by the hysteresis curves of both samples A1, A2, B1, and B2 appear to have pinching effects, this is due to a disturbance when stress reached $20 \mathrm{kN}$ in a reverse direction. This was proven by the physical elastomeric base isolator test results at that load, which was bulging, as shown in Figure 13. Hence, the bulging effect in the horizontal tests shows the potential of sliding but to prove this potential further research is needed such as the use of glass fiber as reinforcement might be 
combined with rubber that has higher hardness, or introducing other types of glass fibers, or even other kinds of fibers in the future research.

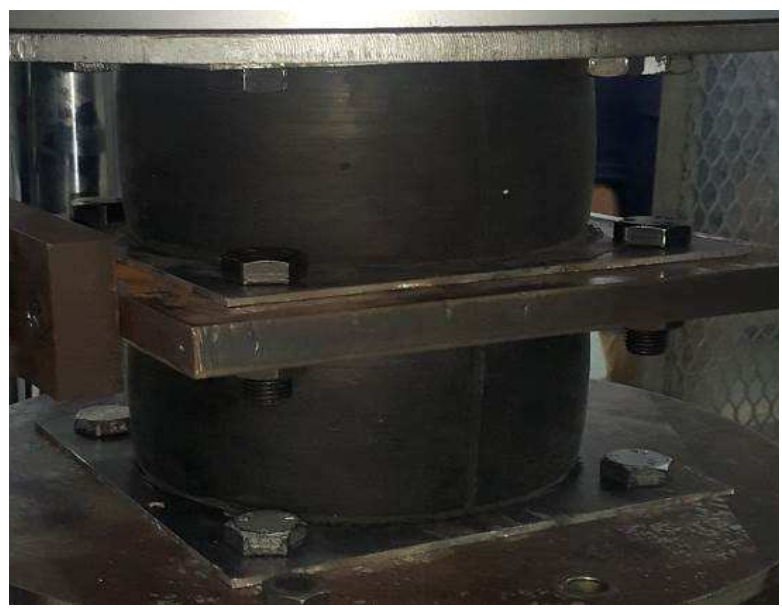

Fig. 13 Bulging effect of samples B1 and B2 in horizontal test

\section{Vertical Test Results}

The compression test is needed to determine the compactness and vertical stiffness of elastomeric isolator composite materials. If there is no data, a vertical test may be replaced by a numerical approach. In the study, there were two samples of elastomeric isolators tested experimentally. The results are shown in Figures 14 and 15.

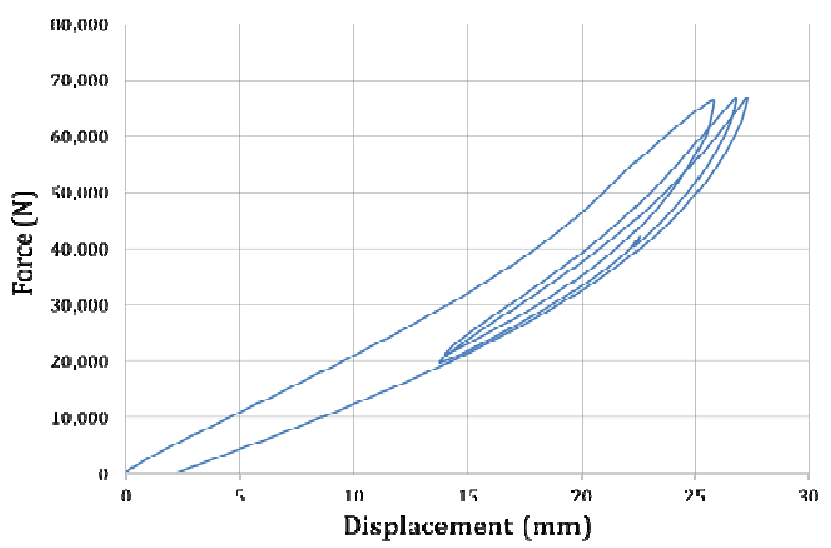

Fig. 14 Results of the force-displacement curve of sample A1 under vertical test

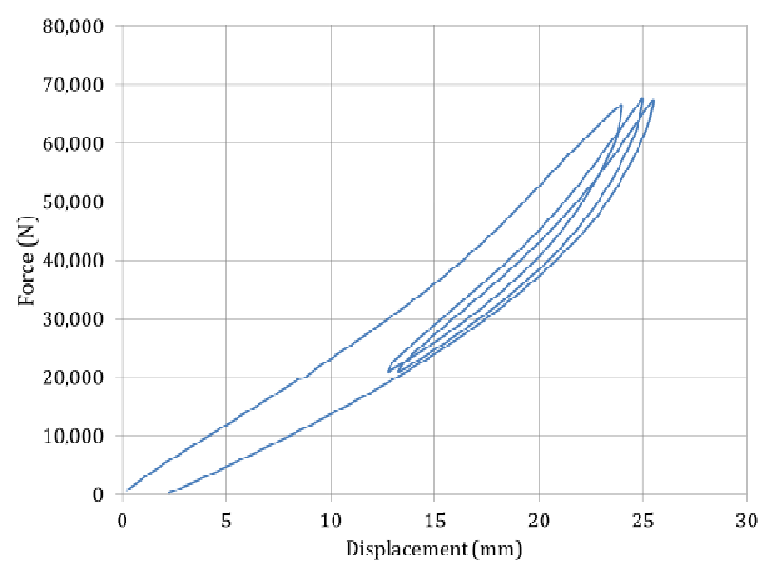

Fig. 15 Results of the force-displacement curve of sample B1 under vertical load
From Figures 14 and 15, it can be seen that the vertical displacement of sample A1 is $28 \mathrm{~mm}$ which is larger than that of sample B1, whereas in case of hardness, sample A has smaller value than sample B. This is due to sampling A has greater stiffness than sample B. This evidence indicates that the composite materials with glass fiber reinforcement work well in improving the stiffness of the elastomeric isolator. The composite of low-hardness rubber with the glass fiber layers as reinforcement has a good impact on the behavior of vertical elastomeric isolators as can be seen in Figure 16.

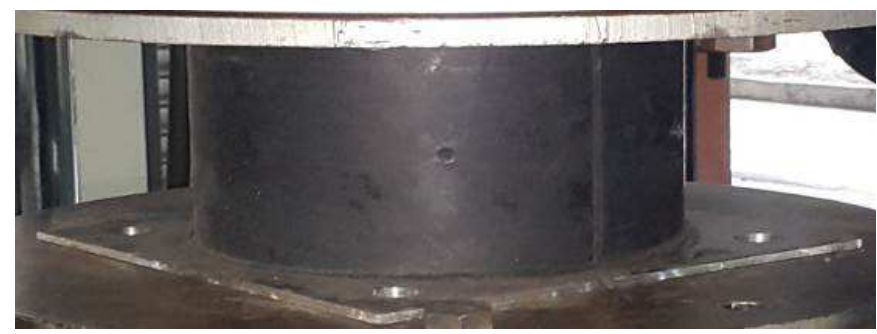

Fig. 16 Vertical-test sample A1 at the vertical displacement of $28 \mathrm{~mm}$

\section{CONCLUSIONS}

The local hyperelastic rubbers selected in the study for research were those with the compositions of hardness 40 and 60. The main reason is that the local hyperelastic rubber with low hardness category (type A) has a high strain but has low stiffness, which is very suitable for typical low-rise buildings since they experience small axial load and have a short natural fundamental period. Vice versa, the hyperelastic rubber with high hardness category (type B) is suitable for high-rise buildings.

In the study, it is worthwhile to note that there was a sliding potential at the initial load of $20 \mathrm{kN}$. This can be seen from the hysteretic curve where there was pinching at the load of $20 \mathrm{kN}$. The combination of rubber layers with other materials that have high ductilities such as steel plate, carbon fiber, or glass fiber plays a critical role in creating the innovative low-cost base isolators.

Overall, the test results of elastomeric isolators using glass fiber as alternative layers are very promising. However, further research is still needed to assure the application of these isolators in real buildings. The local rubber materials are also quite promising for use in the development of lowcost elastomeric base isolators, particularly for low-rise buildings such as public houses (low axial loads/low gravity loads).

\section{NOMENCLATURE}

$K \quad$ stiffness

$E_{c} \quad$ elastic modulus of rubber

A cross-sectional area

$t$ thickness

$G \quad$ shear modulus of elastomer

$S \quad$ shape factor

$F \quad$ shear force

$d \quad$ displacement

$W_{d} \quad$ dissipated energy

$W_{s} \quad$ stored or elastic energy 
Greek letters

$\beta \quad$ equivalent viscous damping ratio

$\Delta_{\max }$ average of positive and negative displacement

$\begin{array}{ll}\text { Subscripts } \\ V & \text { vertical } \\ H & \text { horizontal } \\ r & \text { rubber } \\ \text { eff } & \text { effective } \\ \text { max } & \text { maximum } \\ \text { min } & \text { minimum }\end{array}$

\section{ACKNOWLEDGMENT}

The authors would like to acknowledge for all the facilities gratefully and the supports received to make this research possible.

\section{REFERENCES}

[1] A. B. Habieb, G. Milani, Tavio, and F. Milani. "Low Cost Frictional Seismic Base-Isolation of Residential New Masonry Buildings in Developing Countries: A Small Masonry House Case Study, Open Civil Engineering Journal, V. 11, No. M2, pp. 1026-1035, January 2017.

[2] A. B. Habieb, G. Milani, Tavio, and F. Milani. "An Abaqus User Element for the Structural Implementation of Low-Cost Rubber Seismic Isolators in Masonry Buildings," AIP Conference Proceedings, American Institute of Physics, V. 2040, pp. 090002-1090002-5.

[3] A. B. Habieb, G. Milani, and Tavio. "Two-Step Advanced Numerical Approach for the Design of Low-Cost Unbonded Fiber Reinforced Elastomeric Seismic Isolation Systems in New Masonry Buildings," Engineering Failure Analysis, Elsevier, V. 90, pp. 380-396, August 2018.
[4] A. B. Habieb, G. Milani, Tavio, and F. Milani. "Low Cost Rubber Seismic Isolators for Masonry Housing in Developing Countries," AIP Conference Proceedings, American Institute of Physics, V. 1906, pp. 090012-1-090012-4, 2017.

[5] The Daily Records, "Top 10 Largest Rubber Producing Countries in the World," http://www.thedailyrecords.com/2018-2019-2020-2021/ world-famous-top-10-list/world/largest-rubber-producing-countriesworld-10-top/6857/.

[6] A. B. Habieb, G. Milani, Tavio, and F. Milani. "Low Cost Friction Seismic Base-Isolation of Residential New Masonry Buildings in Developing Countries: A Small Masonry House Case Study," AIP Conference Proceedings, American Institute of Physics, V. 1863, pp. 450009-1-450009-5, 2017.

[7] F. Naeim, and J. M. Kelly. "Design of Seismic Isolated Structures: From Theory to Practice", John Wiley \& Sons, New York, 1999.

[8] J. M. Kelly, and A. Calabrese. "Mechanics of Fiber Reinforced Bearings". Pacific Earthquake Engineering Research Center: 101, 2012.

[9] U. Wijaya, R. Soegiarso, and Tavio. Seismic Performance Evaluation of A Base-Isolated Building, International Journal of Civil Engineering and Technology, 10 (1), 2019, pp. 285-296.

[10] A. B. Habieb, G. Milani, Tavio, and F. Milani. "Seismic Performance of a Masonry Building Isolated with Low-Cost Rubber Isolators," WIT Transactions on the Built Environment, V. 172, pp. 71-82, 2017.

[11] J. M. Kelly, and D. A. Konstantinidis. "Mechanic of Rubber Bearings for Seismic and Vibration Isolation.” John Wiley \& Sons, Ltd, United Kingdom, 2012.

[12] M. D. Symans. "Seismic Protective Systems: Seismic Isolation." FEMA 451, Design Examples, Seismic Isolation, 15-7-1, 2007.

[13] B. T. W. Wijaya, and Tavio. Mechanical Properties of Indonesian Rubber for Low-Cost Base Isolation, International Journal of Civil Engineering and Technology, 10(1), 2019, pp. 884-890.

[14] B. Harsono, and Tavio. Tensile Properties of Fiberglass as Reinforcement of Low-Cost Rubber Base Isolator for Small Houses, International Journal of Civil Engineering and Technology, 10(1), 2019, pp. 1933-1940.

[15] BS EN 15129. "Anti-Seismic Devices." British Standard European Standard Norme Européenne Europäische Norm, 2009. 